\title{
Relationship between renal calculi and the risk of myocardial infarction and stroke: results from the EPIC-Potsdam study
}

\author{
Janine Wirth ${ }^{1 *}$, Steffen Weikert ${ }^{1,3}$, Romina di Giuseppe ${ }^{1}$, Andreas Fritsche ${ }^{4}$, Heiner Boeing ${ }^{1}$ and Cornelia Weikert ${ }^{1,2}$ \\ *Correspondence: janine.wirth@dife.de

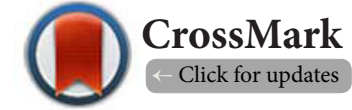 \\ 'Department of Epidemiology, German Institute of Human Nutrition Potsdam-Rehbruecke, Nuthetal, Germany. \\ Institute for Social Medicine, Epidemiology and Health Economics, Charité University Medical Center, Berlin, Germany. \\ ${ }^{3}$ Department of Urology, Charité University Medical Center, Berlin, Germany. \\ ${ }^{4}$ Department of Internal Medicine, Division of Endocrinology, Diabetology, Nephrology, Vascular Disease and Clinical Chemistry, \\ University of Tübingen, Tübingen, Germany.
}

\begin{abstract}
Background: Renal calculi are related to obesity and metabolic syndrome and may indicate an increased risk of cardiovascular disease, but data from prospective cohort studies are sparse. Therefore, the authors investigated the association between renal calculi and the risk of cardiovascular disease endpoints in the European Prospective Investigation into Cancer and Nutrition (EPIC)-Potsdam study.

Methods: The study population comprised 24,490 individuals aged mainly 35-65 years, who were free of cardiovascular diseases at recruitment (1994-1998). Information about the presence of renal calculi at baseline was ascertained via questionnaires. For all incident cases of myocardial infarction and stroke, confirmation was obtained from the attending physician. Hazard rate ratios (HR) were estimated using Cox proportional hazards regression.

Results: During a mean follow-up of 8.1 \pm 1.6 years, 494 cases of cardiovascular disease were identified. Among persons with renal calculi $(n=2,645)$, incidence rates were higher and selected cardiovascular risk factors were more common than among those without renal calculi. In multivariable adjusted models, no association between renal calculi and the risk of cardiovascular diseases $(\mathrm{HR}=1.05,95 \%$ confidence interval (CI): 0.82-1.34) was observed. Endpoint specific analyses revealed similar results. In subanalyses restricted to fatal endpoints, a more than twofold increased risk of fatal myocardial infarction was observed in persons with renal calculi, but this association did not reach statistical significance (HR=2.33, 95\% CI: 0.88-6.13). The HR of fatal stroke was 1.24 (95\% CI: 0.46-3.33) in persons with renal calculi compared to those without.

Conclusions: The authors observed a higher prevalence of cardiovascular risk factors in individuals with renal calculi but no independent relationship between the presence of renal calculi and the risk of myocardial infarction and stroke.
\end{abstract}

Keywords: Cardiovascular disease, nephrolithiasis, prospective, cohort study, kidney stone

\section{Introduction}

The prevalence of renal calculi is increasing worldwide [1], in particular in the Western World [2-5]. This increase is thought to relate to changes in lifestyle and diet [1,4]. Positive associations have been reported between renal calculi and several cardiovascular risk factors: obesity, diabetes, hypertension, metabolic syndrome, atherosclerosis, and chronic kidney disease have all been associated with the development of renal calculi [6-12]. These factors are also related to an increased risk of coronary heart disease (CHD) and/or stroke [13-18]. Thus, pathways that contribute to renal calculi formation, e.g., an increased urinary calcium excretion like in hypertension or obesity [19], may also play a role in the development of subclinical cardiovascular diseases (CVD) and the occurrence of myocardial infarction and stroke. Indeed, an increased risk of myocardial infarction has been observed in persons with renal calculi compared to matched controls [20]. Furthermore, in a recent investigation of three prospective cohort studies [21], the authors reported an increased CHD risk in women but not men with renal calculi. These findings could have clinical implications as the occurrence of renal calculi may indicate an increased risk of future cardiovascular events and could prompt preventive measures. However, data on the association between renal calculi and myocardial infarction and stroke are sparse [20-23]. To shed more light on this issue the relationship between prevalent renal calculi and the risk of myocardial infarction and stroke was investigated in a large German population-based cohort.

\section{Methods}

\section{Study population}

The European Prospective Investigation into Cancer and Nutrition (EPIC)-Potsdam study is part of the large-scale Europewide cohort study EPIC and includes 27,548 individuals (16,644 women and 10,904 men). Participants were recruited between 1994 and 1998 from the general population with the preferred 
ages 35 to 65 years in women and 40 to 65 years in men. The recruitment process was based on addresses from general population registries [24]. The baseline examination included standardized blood pressure measurements, anthropometric measurements, self-administered questionnaires on diet and lifestyle, computer-guided interviews including questions about prevalent diseases, and blood sampling. Blood was collected from $95 \%$ of participants at the Potsdam center. All participants gave their written informed consent and the Ethics Committee of the Federal State Brandenburg approved all study procedures. Information on incident diseases and changes in lifestyle was biennially assessed by self-administered questionnaires [25]. Response rates for all follow-up rounds so far have exceeded $90 \%$ at each occasion.

Since the question about prevalent renal calculi was first implemented in the questionnaire after recruitment has already started, the status of some participants was not provided. Consequently, together with individuals, who were not sure about the existence of renal calculi, 1,488 individuals were excluded from the analyses. Furthermore, 580 participants were not considered, because follow-up data was not available and 780 participants had prevalent CVD or verification of incident cases was not possible. Another 210 individuals were excluded as information on confounding factors was missing. Thereafter, 253 individuals with incident myocardial infarction and 249 individuals with incident stroke were identified. Of nine individuals, who suffered from both myocardial infarction and stroke, only the first event was considered, leaving altogether 494 incident CVD cases (251 myocardial infarctions, 196 ischemic strokes, 14 subarachnoid hemorrhagic strokes, 29 intracerebral strokes, and four undefined strokes).

For additional analyses including relevant biomarkers for inflammation and hyperlipidemia (high-sensitivity C-reactive protein (hsCRP), triglycerides and high density lipoprotein (HDL) cholesterol and total cholesterol), a prospective casecohort design was used consisting of a random sub-cohort $(n=2,500)$ of the EPIC-Potsdam study and all incident cases of myocardial infarction and stroke. After applying the same exclusion criteria as mentioned above, 2,414 participants remained for the case-cohort analysis. Of these, 2,068 individuals belonged to the sub-cohort (including $50 \mathrm{CVD}$ cases and 2,018 non-cases).

\section{Outcome ascertainment}

In the present analysis only medically verified cases were considered for analyses. Potential cases of myocardial infarction or stroke were identified by self-report in one of the four followup questionnaires, by link to the hospital information system of the major hospital in the area and/or by death certificate. To increase sensitivity, the questionnaires included additional questions about typical stroke symptoms [26]. All potential cases were verified according to WHO MONICA criteria by contacting the patients' attending physician and by reviewing medical records of the hospitals and the death certificates [27]. According to the International Statistical Classification of Disease and Related Health Problems 10th revision (ICD10) cases were classified as incident myocardial infarction (ICD-10 I21), ischemic stroke (ICD-10 I63.0-I63.9), intracerebral (ICD-10 I61.0-I61.9) or subarachnoidal hemorrhage (ICD-10 160.0-160.9), or undetermined stroke (ICD-10 164.0-164.9) by two physicians in the study center [28].

\section{Assessment of exposure and covariates}

Information about medical history, including the prevalence of renal calculi, was recorded by trained interviewers during a computer-guided interview. Participants were asked if they ever have been diagnosed with renal calculi and had the response options "yes", "no" or "don't know". Lifestyle characteristics including regular physical exercise and smoking history were documented at baseline by trained personnel during a computer-guided interview. Physical activity was defined as the mean time spent on leisure time physical activities during the summer and winter seasons (hours/week). Habitual alcohol intake during the last 12 months was assessed by a validated food frequency questionnaire [29] and categorized according to recommended upper intake limits (for women: one drink per day ( $\hat{=} 12 \mathrm{~g}$ of alcohol) for men: two drinks per day ( $\hat{=} 24 \mathrm{~g}$ of alcohol)) [30]. Anthropometric data and blood pressure were measured by trained and quality-monitored personnel [31]. Prevalent hypertension was defined as systolic blood pressure $\geq 140 \mathrm{~mm} \mathrm{Hg}$ or diastolic blood pressure $\geq 90 \mathrm{~mm}$ $\mathrm{Hg}$ or self-reporting of a diagnosis or use of antihypertensive medication. The prevalence of diabetes at baseline was evaluated by a physician using information on self-reported medical diagnosis, medication records and dieting behavior. If any uncertainties occurred, the diagnosis was clarified by personal communication with the participant and/or treating physician. Dietary habits including alcohol consumption during the preceding year were assessed by a validated selfadministered food frequency questionnaire [32]. Biomarker levels (hsCRP, total cholesterol, HDL cholesterol, uric acid, and triglycerides) were measured in all incident CVD cases and a random sub-cohort with the automatic ADVIA 1650 analyzer (Siemens Medical Solutions, Erlangen, Germany).

\section{Statistical analysis}

Statistical analysis was performed using SAS software package, release 9.2 (SAS Institute, Cary, NC). All tests were two-sided with $p<0.05$ considered as statistically significant. Age and sex-adjusted baseline characteristics were compared between participants with and without renal calculi using analysis of covariance.

The association between the presence of renal calculi and the risk of CVD (including myocardial infarction and stroke) was examined by estimating sex-adjusted and multivariableadjusted hazard rate ratios (HR) and $95 \%$ confidence intervals (Cl) using Cox proportional hazards regression. Age was used as 
the underlying time variable in the counting process with entry and exit time defined as the participants' age at recruitment and age at time of CVD diagnosis or censoring, respectively. The multivariable-adjusted models included age, sex, educational attainment (vocational school or less (reference), technical colleges, university as indicator variables), physical activity ( $<2$ hour/week, $\geq 2$ hours/week), smoking status (never smoker (reference), past smoker, smoker $<20$ cigarettes/day, smoker $\geq 20$ cigarettes/day as indicator variables), alcohol consumption (men: $0,>0-\leq 12$ grams/day (reference), $>12-\leq 24$ grams/day, $>24$ grams/day, women: $0,>0-\leq 6$ grams/day (reference), $>6$ $-\leq 12$ grams/day, $>12$ grams/day as indicator variables), body mass index and waist circumference (continuously), prevalent diabetes, and hypertension (present/absent). A sub-analysis was performed restricted to fatal events.

In addition, analyses including hsCRP, uric acid, triglycerides, $\mathrm{HDL}$ and total cholesterol were performed in the case-cohort sample. HRs for myocardial infarction, stroke and overall CVD were calculated regarding the presence of renal calculi using a weighted Cox proportional hazards model, modified for the case-cohort design according to Prentice [33]. The validity of the proportional hazards assumption was explored by Kolmogorov-type supremum test and revealed no violation.

\section{Results}

Among 24,490 participants, 2,645 reported a previous diagnosis of renal calculi at baseline (Table 1). These persons were older and more likely to be male compared to individuals without calculi. After adjustment for age and sex, participants with renal calculi had a slightly higher body mass index and waist circumference, were less likely to be smokers and more often had a history of hypertension and diabetes than individuals without renal calculi. The presence of renal calculi was furthermore related to a lower intake of alcohol and a higher intake of water. Moreover, levels of uric acid were slightly higher in individuals with renal calculi (Table 1).

During a mean follow-up of $8.1 \pm 1.6$ years, 494 CVD cases were identified among 24,490 participants ( 2,645 persons with and 21,845 without prevalent renal calculi). Table 2 depicts the estimated HRs of CVD according to the presence of renal calculi. Crude incidence rates of CVD were 2.34 per 1,000 person-years in non-exposed and 3.64 cases per 1,000 person-years in exposed participants. After adjustment for age, sex, smoking status, alcohol consumption, education, physical activity, and prevalent diseases, the status of renal calculi was not associated with developing CVD. This was true for both men and women (men: $\mathrm{HR}=1.12,95 \% \mathrm{Cl}: 0.84-1.50$, women: $\mathrm{HR}=0.91,95 \% \mathrm{Cl}: 0.56-1.49$ ). Further adjustment for dietary factors did not change the risk estimates (data not shown), and endpoint-specific analyses revealed similar results (Table 2 ). Furthermore, restricting stroke cases to ischemic ones did not alter the results ( $\mathrm{HR}$ and $95 \% \mathrm{Cl}$ of ischemic strokes for persons with renal calculi compared to those without: 1.01 (0.68-1.50), $\mathrm{p}=0.97$ ). An additional analysis based on the case-cohort study
Table 1. Baseline characteristics ${ }^{\star}$ of participants according to status of renal calculi in the EPIC-Potsdam Study.

\begin{tabular}{|c|c|c|c|}
\hline \multirow[b]{2}{*}{ Characteristics } & \multicolumn{2}{|c|}{ Renal calculi } & \multirow[b]{2}{*}{ p valu } \\
\hline & $\begin{array}{l}\text { No } \\
(n=21,845)\end{array}$ & $\begin{array}{l}\text { Yes } \\
(n=2,645)\end{array}$ & \\
\hline Age $^{\dagger}$, yrs & $49.8 \pm 9.0$ & $53.8 \pm 8.4$ & $<0.001$ \\
\hline Sex ${ }^{\dagger}, \%$ male & 36.2 & 52.5 & $<0.001$ \\
\hline Body mass index, $\mathrm{kg} / \mathrm{m}^{2}$ & $26.3 \pm 0.0$ & $26.7 \pm 0.1$ & $<0.001$ \\
\hline \multicolumn{4}{|l|}{ Waist circumference, $\mathrm{cm}$} \\
\hline Men & $94.7 \pm 0.1$ & $95.4 \pm 0.3$ & 0.01 \\
\hline Women & $80.5 \pm 0.1$ & $82.0 \pm 0.3$ & $<0.001$ \\
\hline Physical activity, h/wk & $0.98 \pm 0.0$ & $0.96 \pm 0.0$ & 0.64 \\
\hline Smoking, \% & -- & -- & $<0.001$ \\
\hline Never & 47.7 & 49.2 & -- \\
\hline Former & 31.4 & 34.0 & -- \\
\hline Current, $<20$ cig/day & 15.1 & 12.5 & -- \\
\hline Current, $\geq 20$ cig/day & 5.9 & 4.3 & -- \\
\hline Educational attainment, \% & -- & -- & 0.38 \\
\hline No or vocational training & 38.4 & 37.1 & -- \\
\hline Technical school & 24.6 & 25.6 & -- \\
\hline Technical college, university & 37.0 & 37.3 & -- \\
\hline Alcohol intake, g/day & $16.0 \pm 0.1$ & $14.3 \pm 0.3$ & $<0.001$ \\
\hline \multicolumn{4}{|l|}{ Medical History, \% } \\
\hline Prevalent hypertension & 47.3 & 54.8 & $<0.001$ \\
\hline Prevalent diabetes & 4.8 & 5.9 & 0.01 \\
\hline \multicolumn{4}{|l|}{ Nutritional factors ${ }^{*}$} \\
\hline Water, $\mathrm{ml} /$ day & $418 \pm 3.1$ & $486 \pm 8.6$ & $<0.001$ \\
\hline Fruits and vegetables & $191 \pm 0.8$ & $195 \pm 2.3$ & 0.07 \\
\hline Red meat, g/day & $30.2 \pm 0.1$ & $30.5 \pm 0.4$ & 0.39 \\
\hline Processed meat, g/day & $61.5 \pm 0.3$ & $60.6 \pm 0.8$ & 0.28 \\
\hline Fat, g/day & $82.7 \pm 0.1$ & $82.8 \pm 0.3$ & 0.66 \\
\hline Cholesterol, mg/day & $307 \pm 0.6$ & $304 \pm 1.6$ & 0.15 \\
\hline Biomarkers $^{\S}, \mathrm{mg} / \mathrm{dl}$ & $\begin{array}{l}\text { No } \\
(n=1,852)\end{array}$ & $\begin{array}{l}\text { Yes } \\
(n=216)\end{array}$ & p value \\
\hline hsCRP & $1.80 \pm 0.1$ & $1.96 \pm 0.2$ & 0.49 \\
\hline Triglycerides & $130 \pm 2.1$ & $134 \pm 5.8$ & 0.59 \\
\hline Total cholesterol & $191 \pm 1.0$ & $197 \pm 2.8$ & 0.04 \\
\hline HDL cholesterol & $51.7 \pm 0.3$ & $50.9 \pm 0.9$ & 0.43 \\
\hline Uric acid & $4.50 \pm 0.0$ & $4.68 \pm 0.1$ & 0.03 \\
\hline
\end{tabular}

Abbreviations: cig.: cigarettes, EPIC: European Investigation into Cancer and Nutrition, HDL: high.density lipoprotein, hsCRP: high-sensitivity C-reactive protein.

"Baseline characteristics of participants are expressed as age- and sex-adjusted means \pm standard error (SE) or percentages and were compared between participants with and without stones using analysis of covariance. Age and sex were not adjusted and are expressed as mean \pm standard deviation or percentage.

${ }^{\dagger}$ Age and gender distribution were compared between participants with and without stones using Student's unpaired test or the $x^{2}$ test, respectively.

${ }^{*}$ Nutritional intakes are expressed as means \pm SE, adjusted for age, sex and total energy intake.

${ }^{\S}$ Based on a randomised subcohort of the EPIC-Potsdam study. 
design, in which relevant biomarkers were included in the fully adjusted model, did not considerably change the risk estimates ( $\mathrm{HR}=1.15,95 \% \mathrm{Cl}: 0.85-1.57$ for CVD, $\mathrm{HR}=1.18,95 \%$ $\mathrm{Cl}: 0.79-1.79$ for myocardial infarction and $\mathrm{HR}=1.11,95 \% \mathrm{Cl}$ : 0.73-1.67 for stroke). However, in sub-analyses restricted to fatal endpoints, a more than twofold increased risk for fatal myocardial infarction was observed in persons with renal calculi, although this association did not reach statistical significance (Table 2).

Table 2. Hazard rate ratios of cardiovascular diseases according to the presence of renal calculi in the EPIC-Potsdam study.

\begin{tabular}{|c|c|c|c|c|}
\hline & \multicolumn{4}{|c|}{ Renal calculi } \\
\hline & $\begin{array}{l}\text { No } \\
(n=21,845)\end{array}$ & $\begin{array}{l}\text { Yes } \\
(n=2,645)\end{array}$ & & \\
\hline Person-years & 177,658 & 21,388 & -- & -- \\
\hline \multicolumn{5}{|c|}{ Cardiovascular diseases } \\
\hline \multirow[t]{2}{*}{ Cases n (\%) } & $416(1.90)$ & $78(2.95)$ & -- & -- \\
\hline & HR & HR & 95\% CI & p value \\
\hline Model $1^{*}$ & 1 & 1.03 & $0.80,1.31$ & 0.83 \\
\hline Model $2^{\dagger}$ & 1 & 1.05 & $0.82,1.34$ & 0.73 \\
\hline \multicolumn{5}{|l|}{ Fatal CVD } \\
\hline Cases n (\%) & $38(0.18)$ & $11(0.43)$ & -- & -- \\
\hline Model $1^{*}$ & 1 & 1.70 & $0.86,3.38$ & 0.13 \\
\hline Model $2^{\dagger}$ & 1 & 1.66 & $0.83,3.31$ & 0.15 \\
\hline \multicolumn{5}{|c|}{ Myocardial infarction } \\
\hline \multirow[t]{2}{*}{ Cases n (\%) } & $209(0.96)$ & $42(1.59)$ & -- & -- \\
\hline & HR & HR & 95\% CI & p value \\
\hline Model $1^{*}$ & 1 & 1.08 & $0.77,1.51$ & 0.66 \\
\hline Model $2^{\dagger}$ & 1 & 1.13 & $0.80,1.58$ & 0.49 \\
\hline \multicolumn{5}{|c|}{ Fatal myocardial infarction } \\
\hline Cases n (\%) & $16(0.07)$ & $6(0.23)$ & -- & -- \\
\hline Model $1^{*}$ & 1 & 2.32 & $0.89,6.09$ & 0.09 \\
\hline Model $2^{\dagger}$ & 1 & 2.33 & $0.88,6.13$ & 0.09 \\
\hline \multicolumn{5}{|l|}{ Stroke } \\
\hline \multirow[t]{2}{*}{ Cases n (\%) } & $207(0.95)$ & $36(1.36)$ & -- & -- \\
\hline & HR & HR & $95 \% \mathrm{CI}$ & p value \\
\hline Model 1* & 1 & 0.98 & $0.68,1.40$ & 0.90 \\
\hline Model $2^{\dagger}$ & 1 & 0.97 & $0.68,1.39$ & 0.86 \\
\hline \multicolumn{5}{|l|}{ Fatal stroke } \\
\hline Cases n (\%) & $22(0.10)$ & $5(0.19)$ & -- & -- \\
\hline Model $1^{*}$ & 1 & 1.28 & $0.47,3.44$ & 0.63 \\
\hline Model $2^{\dagger}$ & 1 & 1.24 & $0.46,3.33$ & 0.68 \\
\hline
\end{tabular}

Abbreviations: CI: confidence interval, EPIC: European Investigation into Cancer and Nutrition, HR: hazard rate ratio *Adjusted for age and sex.

${ }^{\dagger}$ Like model 1, further adjusted for education (vocational training or less(reference), technical school, university degree), physical activity (continuous in hours/week), smoking (never (reference), past, current $<20$ cigarettes/d, current $\geq 20$ cigarettes/d), alcohol intake (men: $0, \leq 12 \mathrm{~g} / \mathrm{d}$ (reference), $>12-\leq 24 \mathrm{~g} / \mathrm{d},>24 \mathrm{~g} / \mathrm{d}$, women: $0, \leq 6 \mathrm{~g} / \mathrm{d}$ (reference), $>6-\leq 12 \mathrm{~g} / \mathrm{d},>12 \mathrm{~g} / \mathrm{d}$ ), BMI (continuously), waist circumference (continuously), prevalent hypertension and prevalent diabetes (present/absent).

\section{Discussion}

In the present prospective cohort study, which was based on a German population of middle-aged men and women, no association was observed between prevalent renal calculi and the risk of incident CVD (myocardial infarction and stroke).

This finding is contrary to those from previous studies in which an increased risk of CVD was observed among participants with renal calculi. Stoller and colleagues [34] hypothesized a common mechanism behind the development of CVD and renal calculi which is characterized by atherosclerotic-like plaque development. Accordingly, the calcification may erode into the renal papillary interstitium and into the papillary ducts of Bellini and ultimately incite calculus formation. However, this hypothesis could not yet be clarified. Moreover, arterial wall (intima media) thickness was associated with renal calculi in young individuals aged between 15 and 30 years [10]. Thus, arterial wall calcification and the development of renal calculi may be the consequences of impaired or lacking calcification inhibitors.

Recently, in a study based on the US American population, Rule et al., [20] obtained an increased risk of myocardial infarction in persons with renal calculi after adjustment for important comorbidities. However, another explanation for the observed risk increase may be merely due to sharing similar risk factors [22], as these were only roughly captured. In another recent study in Taiwan [23], an increased risk of stroke during the first five years after a diagnosis of urinary calculi was reported compared to matched controls. However, the authors did not take into account lifestyle factors such as smoking, physical activity and alcohol consumption. More recently, Ferraro et al., [21] investigated the association between renal calculi and the risk of CHD in three prospective cohort studies (Nurses' Health Study I, Nurses' Health Study II, and the Health Professionals Follow-up Study) and observed an increased CHD risk in women, but not men, with renal calculi compared to those without.

Those sex differences were not observed in the present study, but important cardiovascular risk factors were more common among stone formers. Indeed, increasing evidence suggests that the development of renal calculi is associated with the presence of important cardiovascular risk factors like hypertension, smoking, obesity, metabolic syndrome, and type 2 diabetes $[7-9,11,22,35]$. However, in the present study a lower percentage of current smokers was observed among participants with renal calculi - when compared to those without - which, actually, may be the result of recommendations to modify their lifestyles because of a renal calculi diagnosis. Further, Domingos et al., [36] assumed that renal calculi are associated with an increased prevalence of chronic diseases including myocardial infarction and stroke using data from a large health survey in Portugal. Due to controversial findings further prospective studies are needed taking into account detailed confounding variables to clarify the relation between renal calculi and CVD, in particular with 
regards to possible gender differences.

Some limitations of the study need to be discussed. The follow-up period is relatively short and the number of CVD cases is rather limited, thus limiting the power to draw strong conclusions in the stratified analyses on major endpoints and fatal cases. Further, the presence of renal calculi was assessed by self-report at baseline. In contrast to the present investigation, previous studies [20-23] used participants with newly diagnosed incident renal calculi, thereby minimizing the threat of exposure misclassification. Furthermore, data on calculi composition and severity of stone disease are missing. In addition, healthy and health-conscious individuals may be overrepresented in the present study population, potentially decreasing the power of detecting an independent association between renal calculi and CVD, particular with small numbers of CVD cases.

Strengths of the study include the prospective cohort design and the application of computer-guided interviews, which are valid assessment tools for the evaluation of medical history, including renal calculi [37]. Furthermore, detailed data on cardiovascular risk factors and measurements of relevant biomarkers were available for the studied cohort, underlining the validity of the observations.

\section{Conclusions}

The present findings do not indicate an independent association of prevalent renal calculi and CVD risk. However, the prevalence of unfavorable cardiovascular health conditions is higher among individuals with renal calculi. The occurrence of renal calculi may, therefore, suggest a targeted screening for cardiovascular risk factors in all patients concerned.

List of abbreviations

EPIC: European Prospective Investigation

into Cancer and Nutrition

CHD: coronary heart disease

$\mathrm{Cl}$ : confidence interval

CVD: Cardiovascular disease

HDL: high density lipoprotein

HR: Hazard rate ratio

hsCRP: high-sensitivity C-reactive protein

ICD-10: International Statistical Classification of Disease

and Related Health Problems 10th revision

Competing interest

The authors declare that they have no competing interests.

Authors' contributions

\begin{tabular}{|l|c|c|c|c|c|c|}
\hline Authors' contributions & JW & SW & RG & AF & HB & CW \\
\hline Research concept and design & -- & -- & -- & -- & $\checkmark$ & $\checkmark$ \\
\hline Collection and/or assembly of data & -- & -- & -- & $\checkmark$ & $\checkmark$ & $\checkmark$ \\
\hline Data analysis and interpretation & $\checkmark$ & $\checkmark$ & $\checkmark$ & $\checkmark$ & $\checkmark$ & $\checkmark$ \\
\hline Writing the article & $\checkmark$ & $\checkmark$ & -- & -- & -- & -- \\
\hline Critical revision of the article & $\checkmark$ & $\checkmark$ & $\checkmark$ & $\checkmark$ & $\checkmark$ & $\checkmark$ \\
\hline Final approval of article & $\checkmark$ & $\checkmark$ & $\checkmark$ & $\checkmark$ & $\checkmark$ & $\checkmark$ \\
\hline Statistical analysis & $\checkmark$ & -- & $\checkmark$ & -- & -- & -- \\
\hline
\end{tabular}

Acknowledgement and funding

The recruitment phase of the EPIC-Potsdam Study was supported by the Federal Ministry of Science, Germany (01 EA 9401), and the European Union (SOC 95201408 05F02). The follow-up was supported by the German Cancer Aid (70-2488Ha I) and the European Community (SOC 98200769 05F02). The funders had no role in study design, data collection and analysis, decision to publish, or preparation of the manuscript. The authors thank all study participants for their cooperation. We are indebted to Wolfgang Fleischhauer for case ascertainment and Ellen Kohlsdorf for data management.

Publication history

EIC: Kevin R. Loughlin, Harvard Medical School, USA.

Received: 17-Jan-2014 Revised: 25-Feb-2014

Accepted: 10-Mar-2014 Published: 22-Mar-2014

\section{References}

1. Romero V, Akpinar $\mathrm{H}$ and Assimos DG. Kidney stones: a global picture of prevalence, incidence, and associated risk factors. Rev Urol. 2010; 12:e86-96. | PubMed Abstract | PubMed Full Text

2. Hesse A, Brandle E, Wilbert D, Kohrmann KU and Alken P. Study on the prevalence and incidence of urolithiasis in Germany comparing the years 1979 vs. 2000. Eur Urol. 2003; 44:709-13. I Article I PubMed

3. Amato $M$, Lusini $M L$ and Nelli F. Epidemiology of nephrolithiasis today. Urol Int. 2004; 72 Suppl 1:1-5. I Article I PubMed

4. Scales CD, Jr., Smith AC, Hanley JM and Saigal CS. Prevalence of kidney stones in the United States. Eur Urol. 2012; 62:160-5. | Article | PubMed Abstract | PubMed Full Text

5. Pearle MS, Calhoun EA and Curhan GC. Urologic diseases in America project: urolithiasis. J Urol. 2005; 173:848-57. I Article I PubMed

6. Jeong IG, Kang T, Bang JK, Park J, Kim W, Hwang SS, Kim HK and Park HK. Association between metabolic syndrome and the presence of kidney stones in a screened population. Am J Kidney Dis. 2011; 58:383-8. I Article I PubMed

7. West B, Luke A, Durazo-Arvizu RA, Cao G, Shoham D and Kramer H. Metabolic syndrome and self-reported history of kidney stones: the National Health and Nutrition Examination Survey (NHANES III) 19881994. Am J Kidney Dis. 2008; 51:741-7. I Article | PubMed

8. Cappuccio FP, Strazzullo P and Mancini M. Kidney stones and hypertension: population based study of an independent clinical association. BMJ. 1990; 300:1234-6. | Article | PubMed Abstract | PubMed Full Text

9. Taylor EN, Stampfer MJ and Curhan GC. Obesity, weight gain, and the risk of kidney stones. JAMA. 2005; 293:455-62. I Article I PubMed

10. Reiner AP, Kahn A, Eisner BH, Pletcher MJ, Sadetsky N, Williams OD, Polak JF, Jacobs DR, Jr. and Stoller ML. Kidney stones and subclinical atherosclerosis in young adults: the CARDIA study. J Urol. 2011; 185:920-5. | Article | PubMed Abstract | PubMed Full Text

11. Taylor EN, Stampfer MJ and Curhan GC. Diabetes mellitus and the risk of nephrolithiasis. Kidney Int. 2005; 68:1230-5. I Article I PubMed

12. Alexander RT, Hemmelgarn BR, Wiebe N, Bello A, Morgan C, Samuel S, Klarenbach SW, Curhan GC and Tonelli M. Kidney stones and kidney function loss: a cohort study. BMJ. 2012; 345:e5287. I Article I PubMed Abstract | PubMed Full Text

13. McGovern PG, Pankow JS, Shahar E, Doliszny KM, Folsom AR, Blackburn $\mathrm{H}$ and Luepker RV. Recent trends in acute coronary heart disease-mortality, morbidity, medical care, and risk factors. The Minnesota Heart Survey Investigators. N Engl J Med. 1996; 334:884-90. | Article | PubMed

14. Weiner DE, Tighiouart H, Amin MG, Stark PC, MacLeod B, Griffith JL, Salem DN, Levey AS and Sarnak MJ. Chronic kidney disease as a risk factor for cardiovascular disease and all-cause mortality: a pooled analysis of community-based studies. J Am Soc Nephrol. 2004; 15:1307- 
Wirth et al. Clinical Nephrology and Urology Science 2014,

\section{5. | Article | PubMed}

15. Galassi A, Reynolds K and He J. Metabolic syndrome and risk of cardiovascular disease: a meta-analysis. Am J Med. 2006; 119:812-9. | Article I PubMed

16. Huxley R, Barzi F and Woodward M. Excess risk of fatal coronary heart disease associated with diabetes in men and women: meta-analysis of 37 prospective cohort studies. BMJ. 2006; 332:73-8. | Article | PubMed Abstract | PubMed Full Text

17. Von Sarnowski B, Putaala J, Grittner U, Gaertner B, Schminke U, Curtze $\mathrm{S}$, Huber R, Tanislav C, Lichy $\mathrm{C}$ and Demarin V et al. Lifestyle risk factors for ischemic stroke and transient ischemic attack in young adults in the Stroke in Young Fabry Patients study. Stroke. 2013; 44:119-25. I Article I PubMed

18. Kastorini CM, Georgousopoulou E, Vemmos KN, Nikolaou V, Kantas D, Milionis HJ, Goudevenos JA and Panagiotakos DB. Comparative analysis of cardiovascular disease risk factors influencing nonfatal acute coronary syndrome and ischemic stroke. Am J Cardiol. 2013; 112:34954. | Article | PubMed

19. Mente A, Honey RJ, McLaughlin JM, Bull SB and Logan AG. High urinary calcium excretion and genetic susceptibility to hypertension and kidney stone disease. J Am Soc Nephrol. 2006; 17:2567-75. I Article I PubMed

20. Rule AD, Roger VL, Melton LJ, 3rd, Bergstralh EJ, Li X, Peyser PA, Krambeck AE and Lieske JC. Kidney stones associate with increased risk for myocardial infarction. J Am Soc Nephrol. 2010; 21:1641-4. I Article I PubMed Abstract I PubMed Full Text

21. Ferraro PM, Taylor EN, Eisner BH, Gambaro G, Rimm EB, Mukamal KJ and Curhan GC. History of kidney stones and the risk of coronary heart disease. JAMA. 2013; 310:408-15. I Article | PubMed

22. Hamano S, Nakatsu H, Suzuki N, Tomioka S, Tanaka M and Murakami S. Kidney stone disease and risk factors for coronary heart disease. Int J Urol. 2005; 12:859-63. | Article | PubMed

23. Chung SD, Liu SP, Keller JJ and Lin HC. Urinary calculi and an increased risk of stroke: a population-based follow-up study. BJU Int. 2012; 110:E1053-9. I Article | PubMed

24. Boeing $H$, Korfmann A and Bergmann MM. Recruitment procedures of EPIC-Germany. European Investigation into Cancer and Nutrition. Ann Nutr Metab. 1999; 43:205-15. I Article I PubMed

25. Bergmann MM, Bussas $U$ and Boeing $\mathrm{H}$. Follow-up procedures in EPICGermany--data quality aspects. European Prospective Investigation into Cancer and Nutrition. Ann Nutr Metab. 1999; 43:225-34. | Article | PubMed

26. Weikert C, Berger K, Heidemann C, Bergmann MM, Hoffmann K, Klipstein-Grobusch $\mathrm{K}$ and Boeing $\mathrm{H}$. Joint effects of risk factors for stroke and transient ischemic attack in a German population: the EPIC Potsdam Study. J Neurol. 2007; 254:315-21. I Article I PubMed

27. Tunstall-Pedoe $H$, Kuulasmaa K, Amouyel P, Arveiler D, Rajakangas AM and Pajak A. Myocardial infarction and coronary deaths in the World Health Organization MONICA Project. Registration procedures, event rates, and case-fatality rates in $\mathbf{3 8}$ populations from 21 countries in four continents. Circulation. 1994; 90:583-612. | Article I PubMed

28. World Health Organisation. International Statistical Classification of Diseases and Related Health Problems 10th Revision. WHO 2010| Website

29. Kroke A, Klipstein-Grobusch K, Voss S, Moseneder J, Thielecke F, Noack $\mathrm{R}$ and Boeing $\mathrm{H}$. Validation of a self-administered food-frequency questionnaire administered in the European Prospective Investigation into Cancer and Nutrition (EPIC) Study: comparison of energy, protein, and macronutrient intakes estimated with the doubly labeled water, urinary nitrogen, and repeated 24-h dietary recall methods. Am J Clin Nutr. 1999; 70:439-47. | Article I PubMed

30. Schutze M, Boeing H, Pischon T, Rehm J, Kehoe T, Gmel G, Olsen A, Tjonneland AM, Dahm CC, Overvad K and Clavel-Chapelon F et al. Alcohol attributable burden of incidence of cancer in eight European countries based on results from prospective cohort study. BMJ. 2011; 342:d1584. | Article | PubMed Abstract | PubMed Full Text

31. Kroke A, Bergmann MM, Lotze G, Jeckel A, Klipstein-Grobusch K and Boeing $\mathrm{H}$. Measures of quality control in the German component of the EPIC study. European Prospective Investigation into Cancer and Nutrition. Ann Nutr Metab. 1999; 43:216-24. I Article I PubMed

32. Bohlscheid-Thomas S, Hoting I, Boeing $\mathrm{H}$ and Wahrendorf J. Reproducibility and relative validity of energy and macronutrient intake of a food frequency questionnaire developed for the German part of the EPIC project. European Prospective Investigation into Cancer and Nutrition. Int J Epidemiol. 1997; 26 Suppl 1:S71-81. | Article | PubMed

33. Prentice R. A case-cohort design for epidemiologic cohort studies and disease prevention trials. Biometrika. 1986; 73:1-11. | $\underline{\text { Article }}$

34. Stoller ML, Meng MV, Abrahams HM and Kane JP. The primary stone event: a new hypothesis involving a vascular etiology. J Urol. 2004; 171:1920-4. | Article | PubMed

35. Jeong IG, Ro JY, Kim SC, You D, Song C, Hong JH, Ahn H and Kim CS Extranodal extension in node-positive bladder cancer: the continuing controversy. BJU Int. 2011; 108:38-43. I Article I PubMed

36. Domingos F and Serra A. Nephrolithiasis is associated with an increased prevalence of cardiovascular disease. Nephrol Dial Transplant. 2011; 26:864-8. | Article | PubMed

37. Bergmann MM, Jacobs EJ, Hoffmann K and Boeing H. Agreement of selfreported medical history: comparison of an in-person interview with a self-administered questionnaire. Eur J Epidemiol. 2004; 19:411-6. | Article | PubMed

\section{Citation:}

Wirth J, Weikert S, di Giuseppe R, Fritsche A, Boeing H and Weikert $C$. Relationship between renal calculi and the risk of myocardial infarction and stroke: results from the EPIC-Potsdam study. Clin Nephrol Urol Sci. 2014; 1:3. http://dx.doi.org/10.7243/2054-7161-1-3 